\title{
A GESTÃO CENTRO-PERIFERIA NA INTERNACIONALIZAÇÃO DE MESTRADOS EXECUTIVOS
}

\author{
LA GESTIÓN ENTRE EL CENTRO-LA PERIFERIA EN LA \\ INTERNALIZACIÓN DE MAESTRADOS EJECUTIVOS \\ CENTER-PERIPHERY MANAGEMENT IN THE \\ INTERNATIONALIZATION OF EXECUTIVE MASTERS
}

\author{
Ana Christina Celano TEIXEIRA ${ }^{1}$ \\ Sergio Eduardo de Pinho Velho WANDERLEY ${ }^{2}$ \\ Fátima Bayma de OLIVEIRA ${ }^{3}$
}

RESUMO: Este artigo analisa o processo de internacionalização do International Masters Program for Managers (IMPM), mestrado criado e ainda dirigido por Henry Mintzberg, a partir do estabelecimento de sua parceria internacional, em 2012, com uma instituição de ensino brasileira. O IMPM foi concebido por Mintzberg, em 1995, como um modelo heterodoxo que desafiaria o modelo de MBA tradicional dos EUA. Afinal, Mintzberg sugere que prevaleçam "Managers Not MBAs". A partir de uma perspectiva crítica, verificamos que o IMPM, mesmo propondo uma valorização da cultura dos diferentes locais em que se hospedam os módulos internacionais, não escapa da lógica anglo-saxã de imposição de conhecimento. Esperamos que a consideração do fenômeno de internacionalização dos programas internacionais de educação em gestão, a partir de uma perspectiva crítica, possa amplificar as vozes dos países periféricos e proporcionar um maior equilíbrio entre a produção e consumo de conhecimento em gestão no cenário mundial contemporâneo. É necessário trabalhar sobre a perspectiva de que haja um movimento mais dialógico entre centro e periferia, onde não só os aspectos culturais destes países sejam considerados, mas também sua produção de conhecimento possa ser reconhecida.

PALAVRAS-CHAVE: Henry Mintzberg. IMPM. Internacionalização de mestrados executivos.

RESUMEN: Este artículo analisa el proceso de internalización de la Internacional Master Program for Managers (IMPM), maestrado creado que todavia es dirigido por Henry Mintzberg, a partir del establecimiento de compañerismo internacional, em 2012, como una institución de educación brasilera. El IMPM fue creado por Mintzberg, em 1995, como um modelo heterodoxo que desafiaria el modelo de MBA

\footnotetext{
${ }^{1}$ Faculdades Ibmec (Ibmec), Rio de Janeiro - Rj - Brasil. Professora Adjunta do programa de Mestrado em Administração do Ibmec e professor visitante do EBAPE/FGV. E-mail: ana.teixeira@fgv.br.

${ }^{2}$ Universidade do Grande Rio (Unigranrio), Rio de Janeiro - RJ - Brasil. Professor Adjunto do Programa de Pós-Graduação em Administração da Unigranrio. E-mail: sergiow.gaz@terra.com.br.

${ }^{3}$ Fundação Getúlio Vargas (Fgv), Rio de Janeiro - RJ - Brasil. Professora Titular dos cursos de Mestrado e Doutorado em Administração da Escola Brasileira de Administração Pública e de Empresas (EBAPE/FGV). E-mail: fatima.oliveira@fgv.br.
}

RPGE - Revista on line de Política e Gestão Educacional, Araraquara, v. 22, n. esp.1, p. 244-264, mar., 2018. 
tradicional de los EUA. Al final Mintzberg sugiere que prevalezcan Managers Not MBAs. A partir de uma perspectiva crítica, verificamos que el IMPM, mismo proponiendo una valorarización de la cultura de los diferentes locales em que se hospedan los módulos internacionales, no escapa de la lógica anglo-sajona de imposición de conocimientos. Esperamos que la consideración delfenómeno de internacionalización de los programas internacionales de educaciónen gestión, a partir de una perspectiva critica, pueda amplificar las voces de los países perifericos y proporcionar un mayor equilibrio entre la produccción y consumo de conocimiento en gestión, en el escenario mundial contemporáneo. Es necesario trabajar en una perspectiva en la cual exista un movimiento mas dialogable entre el centro y la periferia, donde no solo los aspectos culturales de estos países sean considerados, mas también la produccción de conocimiento pueda ser reconocida.

PALABRAS CLAVES: Henry Mintzberg. IMPM. Internalización de Maestrados Ejecutivos.

ABSTRACT: This article analyzes the process of internationalization of the International Masters Program for Managers (IMPM) started in 2012 from a partnership established with a Brazilian institution. Created in 1995 by Henry Mintzberg - also the current director - the IMPM adopted a heterodox model challenging the US traditional MBA model, Mintzberg's moto "Managers, Not MBA" suggests a new focus on managers instead of overemphasizing analysis and technique. From a critical perspective, this study identifies that, although proposing an appreciation of the culture of the different places where the international modules are hosted, the IMPM still adopts the Anglo-Saxon logic of knowledge imposition. The study reflects the expectation that, when considering the internationalization of management educational programs, from a critical point of view, the voices of peripheral countries are heard, promoting a better balance between the production and consumption of knowledge on management in the contemporary global context. It is necessary, therefore, to work in order to create a more dialogical movement between center and periphery, establishing a dynamic that considers not only cultural aspects, but also that recognizes the production of knowledge in both contexts.

KEYWORDS: Henry Mintzberg. IMPM. Internationalization of Executive Masters.

\section{Introdução}

Desde tempos imemoriais a divisão histórica e geográfica do mundo esteve relacionada com a divisão do conhecimento. No entanto, nem sempre dentro do atual cenário contemporâneo, frente ao fenômeno da globalização e do surgimento dos países emergentes, fica aparente a existência e a consideração dos diferentes locais de enunciação no que diz respeito às diferenças e às assimetrias de poder que envolvem estas relações e espaços (BERTERO, 2013; MIGNOLO, 2000, 2011). 
Nesse sentido cabe observar um fenômeno cada vez mais constante que diz respeito ao estabelecimento de parcerias internacionais entre países e instituições de ensino superior (ALADIPANI; ROSA, 2011). Afinal, o atual ambiente global parece demandar trocas e interações mais dinâmicas e intensas e nesse processo os países considerados centrais têm buscado de maneira recorrente novas parcerias com países emergentes ou periféricos (MIGNOLO, 2011).

De acordo com Banerjee e Linstead (2004) estamos vivenciando, de fato, uma era cada vez mais global, porém, ao mesmo tempo, cada vez mais informada e configurada pelo pensamento econômico neoliberal. Desta forma a definição de quem ou o quê constitui o "outro internacional" depende de quem está fazendo as perguntas e, muitas vezes, essas perguntas se perdem na pesquisa sobre a gestão internacional, principalmente quando esta não leva em consideração as relações de poder assimétricas encontradas no contexto internacional (DOS SANTOS, 2011).

Dentro da perspectiva desta pesquisa, globalização, modernidade, colonialidade e dominação, surgem de forma sempre entrelaçada e transversal uma vez que estes conceitos estejam imbricados de forma indistinta. No que tange o conceito de dominação, uma boa parte das teorias sobre poder trata este processo de forma em que atores estabelecem influência através da construção de valores ideológicos que se tornam hegemônicos (ou dominantes). Fleming e Spicer $(2014,2007)$ argumentam que há pouca coerção ou manipulação ocorrendo abertamente nesta face do poder. Em vez disso, a dominação como dimensão do poder "molda nossas próprias preferências, atitudes e perspectivas políticas" (FLEMING; SPICER, 2007, p. 19). Essa ideia se baseia em Lukes (2005) conhecido por sua "visão radical" do poder, que compreende o poder como atividade política de tal ordem que define o próprio terreno em que os atores políticos compreendem sua situação no sistema-mundo.

É a partir desta perspectiva que tratamos o fenômeno do estabelecimento de parcerias entre escolas de gestão internacionais, o que envolve sua conexão com a dominação do conhecimento entre países do centro e da periferia, estes também denominados como países emergentes, onde no cenário atual se destacam nomes como Brasil, China, Índia e África do Sul entre outros (FARIA, 2013; TOYOSHIMA, 2007; ZAJDA, 2005).

Assim, pretendemos, por meio desta pesquisa, verificar como ocorreu o processo de estabelecimento de parceria internacional, em 2012, entre o International Masters Program for Managers (IMPM), mestrado internacional criado e ainda dirigido por 
Henry Mintzberg no ano de 1995, com uma instituição de ensino brasileira. A negociação teve como objetivo o estabelecimento de uma parceria acadêmica que envolve a realização anual de um dos cinco módulos do programa, com duas semanas de duração, na cidade do Rio de Janeiro sob a corresponsabilidade da instituição de ensino local.

Para atingir este objetivo foi utilizada uma abordagem qualitativa com a realização de oito entrevistas em profundidade com membros do corpo docente e diretivo de ambas as instituições, responsáveis pelo processo de estabelecimento da parceria para realização do módulo Brasil do programa, incluindo neste grupo seu idealizador, o professor Henry Mintzberg.

A relevância da pesquisa está embasada na discussão de diversos autores (CUNLIFFE; LINSTEAD, 2009; MINTZBERG; GOSLING, 2002; ZAJDA, 2005) de que os processos de internacionalização pelo qual passam os programas de educação em gestão apontam de maneira recorrente a existência de uma rota rumo aos países emergentes, principalmente Brasil, Índia e China, o que demanda um olhar mais atento à compreensão da dinâmica que envolve especificamente estes países no contexto de um novo desenho global no campo da educação em gestão (HURRELL, 2010; DOS SANTOS, 2011).

\section{Referencial teórico}

Antes de qualquer outra consideração, no que tange a apresentação das características do IMPM, cabe ressaltar sua tipicidade. Afinal, o programa pode ser facilmente considerado como um clássico curso de mestrado, de acordo com os padrões de um MBA internacional, oferecido por países desenvolvidos, ricos ou centrais, pois tem sua base acadêmica e administrativa operando entre Canadá e Inglaterra, e, além disso, funciona integralmente sob a égide da língua inglesa. Cabe ainda ressaltar que o programa recebeu em 2016 o reconhecimento internacional como um dos melhores cursos de mestrado internacional pelo relatório Global Focus realizado pela European Foundation for Management Development (EFMD) (Management Development Network).

No entanto, o IMPM assume um discurso parcialmente divergente desta imagem, na medida em que reforça em seu discurso institucional que não possui origem nos Estados Unidos, nem tão pouco pode ou quer ser considerado como um MBA. Na

RPGE - Revista on line de Política e Gestão Educacional, Araraquara, v. 22, n. esp.1, p. 244-264, mar., 2018. 
verdade o programa, apesar de sua posição próxima ao centro pela origem anglo-saxã mantida pelo vínculo com Canadá e Inglaterra, defende uma proposta reflexiva e de ruptura ao modelo padrão dos cursos de MBA dominantes e ortodoxos.

Cabe lembrar que a proposta do programa e sua criação nasce com Henry Mintzberg e Jonathan Gosling, no ano de 1996, com o compromisso de considerar não apenas o consumo, mas também a existência dos conhecimentos locais em gestão em um cenário mundial (MINTZBERG, 2005). Ressalte-se ainda que Mintzberg é autor de livros em que condena o modelo tradicional dos MBA dos EUA, o que já deixa claro no título do livro Managers Not MBAs (MINTZBERG, 2004).

Assim, o IMPM se constitui em sua origem, em um programa de mestrado internacional de certa forma ambivalente, que adota há vinte anos um modelo de curso que vem se adaptando a novas configurações mundiais ao alterar suas parceiras ao longo do tempo e ao estar hoje presente em cinco países, sendo três deles denominados emergente: Índia (desde 1995), China (desde 2011) e Brasil (desde 2012).

O IMPM foi criado em 1996 e desta forma pode-se considerar que seja um pioneiro em comparação com os demais programas internacionais em gestão, pois é um dos primeiros a iniciar sua atuação no campo internacional em termos de parcerias com instituições de educação em diversos locais (MINTZBERG, 2005).

Os cinco países que participaram dos primeiros ciclos do programa foram: Canadá, Inglaterra, Índia, Japão e França ${ }^{4}$. Desde o princípio o IMPM foi criado com a proposta de funcionar de maneira equilibrada com as instituições parceiras: o Indian Institute of Management, em Bangalore (IIMB); o Insead, em Fontainebleu, França; a Faculty of Management da Universidade de Lancaster, na Inglaterra; a Faculty of Management da Universidade de McGill, em Montreal, Canadá; e no Japão, de um grupo de professores oriundos de três instituições, Universidade de Hitsosubashi, Universidade de Kobe e Instituto Japonês Avançado de Ciência e Tecnologia (mais tarde, também o Instituto de desenvolvimento da Coreia do Sul, em Seul).

Por outro lado, devemos observar que o programa mantém desde então, sua administração concentrada entre as Universidades de Lancaster (Inglaterra) e a Universidade McGill (Canadá), instituições situadas no hemisfério Norte e dessa forma considerados como países centrais.

${ }^{4}$ Disponível em: <http://www.impm.org/program>. Acesso em: 30 nov. 2017.

RPGE - Revista on line de Política e Gestão Educacional, Araraquara, v. 22, n. esp.1, p. 244-264, mar., 2018. 
O programa funciona por meio de períodos letivos denominados ciclos. Cada ciclo tem a duração de dezoito meses e funciona com aulas presenciais de duas semanas em cada um dos países parceiros com intervalos de três meses. Após estes 18 meses os participantes podem optar ou não em escrever uma dissertação de mestrado para obter o título de mestres. Esse título pode ainda ter dupla acreditação das universidades McGill e Lancaster, ou de somente uma delas.

Os períodos do programa em cada país são chamados de módulos e a cada um deles é atribuído um 'mindset' ou modelo mental, que tem por objetivo relacionar conceitos locais do país anfitrião ao aprendizado em gestão. Desde o início do programa em 1996 os 'mindsets' se mantém inalterados e atualmente acontecem em correspondência aos países parceiros da seguinte maneira: Inglaterra/reflexão, Canadá/análise, Índia/visão de mundo, China/colaboração, Brasil/ação.

O IMPM tem o objetivo de ser um programa direcionado para profissionais experientes, por isso só admite a inscrição de profissionais atuantes na função de gestores com mais de quinze anos de atuação. Durante seu funcionamento o IMPM contou com um corpo discente de executivos de várias nacionalidades e representantes de um vasto espectro de áreas de negócios.

\section{Globalização, países emergentes e o novo cenário global}

A globalização pode estar sendo experimentada em muitos lugares como uma força discriminatória e opressiva influenciando os países em várias frentes inclusive nos campos da gestão e da educação (SOUDIEN, 2005; FARIA, 2010). O surgimento de países com economias emergentes como Brasil, Rússia, China e Índia, na ordem econômica global seria um desdobramento deste fenômeno e de suas implicações para a produção, a disseminação e o consumo de conhecimento (HURRELL, 2010; SOUDIEN, 2005).

Este cenário traz à tona a necessidade de compreensão de mecanismos envolvidos em relações assimétricas de poder. Neste sentido, houve muitas tentativas para mapear as diferentes formas que o poder assume em organizações (CLEGG et al, 2006; HARDY; CLEGG, 1996; PFEFFER, 1981). Uma das distinções mais marcantes na literatura é entre teorias episódicas de poder (o exercício direto do poder) e as formas sistemáticas de influência (poder que está congelado em estruturas institucionais mais duradouras) (CLEGG, 1989; LAWRENCE; MALHOTRA; MORRIS, 2012). Estas duas 
dimensões amplas foram ainda divididas e reclassificadas por Fleming e Spice (2014, 2007) em quatro outras dimensões: a coerção, manipulação, dominação e subjetivação.

Neste caso a dominação representa uma das faces do poder, que dentro desta perspectiva pode ser considerada sistêmica porque mobiliza recursos institucionais, ideológicos e discursivos para influenciar a atividade organizacional. Como tal, ela atua como uma face menos visível do que atos evidentes e explícitos de poder (FLEMING; SPICER, 2014).

Uma boa parte das teorias do poder organizacional trata do processo de dominação de forma em que atores estabelecem influência através da construção de valores ideológicos que se tornam hegemônicos (ou dominantes). Fleming e Spicer $(2014,2007)$ argumentam que há pouca coerção ou manipulação ocorrendo abertamente nesta face do poder. Em vez disso, a dominação como dimensão do poder tende a formatar ou moldar as pretensas preferências, atitudes e mesmo as perspectivas políticas (FLEMING; SPICER, 2007).

Da mesma maneira, Lukes (2005) compreende o poder como atividade política de tal ordem que define o próprio terreno em que os atores envolvidos no jogo do poder compreendem sua situação organizacional:

"Não é o exercício supremo e insidioso do poder que pode impedir que as pessoas, em qualquer grau, deixem de ter queixas e que moldem suas percepções, cognições e preferências de tal maneira que aceitam seu papel na ordem das coisas existentes, quer por poderem ver ou imaginar alternativa a elas, ou que vejam isso como natural e imutável?" (LUKES, 2005, p. 24).

Esta abordagem do poder faz a seguinte pergunta: como são construídas as relações hierárquicas arbitrárias para parecerem inevitáveis, naturais e, portanto, inquestionáveis?

Assim, cabe considerar, que segundo Tikly (1999), no que tange as organizações na área de educação existe uma perspectiva dominante a ser adotada, que vêm forçando de maneira sutil a que o mundo obedeça a seus critérios e padrões, sem exceção desenvolvidos em países centrais. Ou seja, notadamente reforçando a problematização da dominação, no campo da gestão, entre países como Estados Unidos e Inglaterra com países menos desenvolvidos ou periféricos, como é o caso dos países emergentes.

\section{Globalização e educação em gestão}

RPGE - Revista on line de Política e Gestão Educacional, Araraquara, v. 22, n. esp.1, p. 244-264, mar., 2018. 
Ao estudarmos o fenômeno do estabelecimento de parcerias entre instituições de ensino internacionais no âmbito de cursos de pós-graduação em gestão, devemos considerar que um programa como o IMPM, que assume uma proposta globalizada e multicultural deveria estar imbricado no que Santos (2006) identifica como a necessidade de uma ação global que de fato acontece através de uma produção local ou localizada.

Nesse sentido, Santos (2006) faz uma distinção entre dois modos principais de produção de globalização. O localismo globalizado é o processo pelo qual um determinado fenômeno é globalizado com sucesso, seja a atividade mundial da multinacional, a transformação do idioma Inglês em uma língua franca, a globalização do fast food americano ou música popular, a adoção de programas como os MBAs em relação à educação internacional em gestão, ou a adoção mundial das mesmas leis de propriedade intelectual, patentes ou de telecomunicações promovida agressivamente pelos EUA e pelos países centrais. Neste modo de produção de globalização o que se globaliza é o vencedor de uma luta pela apropriação ou valorização de recursos ou para o reconhecimento de uma diferença hegemônica, cultural, racial, sexual, étnica, religiosa ou regional. Esta vitória traduz a capacidade de ditar os termos da integração, da competição e da inclusão.

O segundo processo de globalização, o globalismo localizado consiste no impacto específico nas condições locais que são produzidos pelas práticas e imperativos transnacionais que decorrem dos localismos globalizados. Para responder a esses imperativos transnacionais, as condições locais são desintegradas, oprimidas, excluídas, desestruturadas e, eventualmente, reestruturadas como inclusão subalterna. Tais 'globalismos' localizados incluem: a eliminação do comércio tradicional e agricultura de subsistência, a criação de enclaves de comércio livre ou zonas, a destruição e desmatamento maciço de recursos naturais, a fim de pagar a dívida externa; dumping ecológico ("compra" pelos países do Terceiro Mundo de lixos tóxicos produzidos nos países capitalistas centrais, a fim de pagar a dívida externa).

Assim, grande parte deste tema refere-se às diferentes nuances da subalternidade a que os países periféricos estarão submetidos dentro do escopo de um programa internacional de educação em gestão (SANTOS, 2006).

Cabe indagar então se estas mudanças, a maior parte delas ocorridas na área econômica, virão acompanhadas de transformações sociais e se serão suportadas por um sistema de educação próprio, capaz de criar seus padrões e não apenas importar os 
padrões já estabelecidos e impostos há tempos pelos países desenvolvidos. Para isso se torna relevante refletir no seguinte sentido: será que os países emergentes que hoje integram programas internacionais de educação em gestão escolheram participar de determinado programa? Sempre foram por eles "escolhidos"? Ou, Como se deu na percepção dos envolvidos a relação para o estabelecimento da parceria?

\section{Metodologia}

Esta pesquisa adotou uma abordagem qualitativa de cunho interpretativo. Esta escolha se baseou em alguns pressupostos como a crescente complexidade do fenômeno estudado frente à globalização e a rapidez com que as mudanças se operam na área da gestão internacional. Como ressaltado por Miles e Huberman (1994), os estudos sociais acontecem dentro do mundo real e exercem impactos reais sobre a vida das pessoas e sobre as dinâmicas sociais, operando continuas transformações.

O estudo seguiu uma perspectiva crítica para repensar os contornos e propósitos das parecerias internacionais estabelecidas entre instituições de ensino no que tange a educação em de gestão, principalmente se alinhada com as mudanças e deslocamentos globais e seguindo uma visão sobre a influência de vários destes assuntos envolvidos em seu desenvolvimento e processo de transformação.

Podemos adicionar a estes argumentos que existe respaldo na literatura que nos diz que a boa pesquisa, a partir de uma perspectiva crítica, é aquela que permite uma compreensão qualitativamente nova de fragmentos relevantes da realidade social, alternativas de comportamentos e fatos novos para a ação social (ALVESSON; SKOLDBERG, 2000).

Nesta pesquisa foram utilizadas três fontes de dados, tanto primárias quanto secundárias: (i) entrevistas com profissionais do corpo docente e administrativo, tanto do IMPM quanto da instituição de ensino local com roteiros semiestruturados (ii) análise documental longitudinal, e (iii) observação direta. Com estes dados buscamos não nos fixar em apenas uma fonte, nos aproximando de uma triangulação (JICK, 1979).

As entrevistas foram realizadas nos anos de 2013 e 2014 no Rio de Janeiro. A técnica de seleção dos entrevistados foi proposital, envolvendo oito entrevistas pessoais, em profundidade com membros atuais do Programa (IMPM) ligados a formação,

RPGE - Revista on line de Política e Gestão Educacional, Araraquara, v. 22, n. esp.1, p. 244-264, mar., 2018. 
estruturação e estabelecimento de parcerias locais, além dos membros da instituição brasileira com a qual a parceria foi estabelecida em 2012.

A análise documental foi feita com base em dois tipos de documentos que foram coletados para: (i) documentos internos como - documentos oficiais do IMPM, sites, apostilas, registros históricos, contratos com outras instituições parceiras, planejamentos estratégicos, fotos de cursos, levantamento do perfil demográfico dos participantes ao longo do tempo e (ii) documentos de domínio público como - levantamento da imprensa sobre o IMPM, depoimentos livres em mídias de domínio público, e sites e/ou blogs de ex-alunos e instituições parceiras e textos acadêmicos e empresariais sobre o Programa.

Estes dados foram essenciais, pois possibilitaram uma contextualização mais rica do programa e aumentaram a confiabilidade dos dados obtidos nas entrevistas, já que documentos "são produtos 'em tempo' e componentes significativos do cotidiano; complementam, completam e competem com a narrativa e a memória" (SPINK, 1999, p. 126).

O resultado da observação foi somado a um diário de campo que os pesquisadores mantiveram para relatar suas observações sobre as questões investigadas durante a realização da pesquisa (CZARNIAWSKA, 2008; LOFLAND; LOFLAND, 1995).

Com exceção da nominação do fundador do programa, Henry Mintzberg, que autorizou a exposição seu nome e seu depoimento, todos os demais entrevistados, membros do corpo docente e diretivo do programa e da instituição local, terão suas identidades preservadas.

As entrevistas foram transcritas e analisadas, assim como todo o conjunto de documentos, observações e notas de campo. Todo o conjunto de dados obtido foi submetido à codificação temática em categorias prévias para identificação de temas (MILES; HUBERMAN, 1994).

De toda forma, e com este cenário em mente, foi a partir do referencial teórico e da questão de pesquisa, que foram construídas, a priori, duas categorias que nos permitiram identificar e problematizar os dados coletados.

\section{Análise e discussão de resultados}

As categorias prévias utilizadas para a análise foram a 'Globalização e educação em gestão' e 'A inserção dos países emergentes na agenda do IMPM'. Desta maneira, a seguir a análise será apresentada seguindo estas duas divisões.

RPGE - Revista on line de Política e Gestão Educacional, Araraquara, v. 22, n. esp.1, p. 244-264, mar., 2018. 
Globalização e educação em gestão

Ao nos determos na primeira categoria de análise devemos recuperar que o objetivo foi procurar problematizar os impactos da globalização através do estabelecimento de uma parceria internacional entre instituições de ensino superior. Assim, investigamos quais teriam sido as principais motivações do IMPM, para a escolha dos países onde atua especialmente os países emergentes, e como se desenvolveu ao longo do tempo seu processo de internacionalização. Além disso, analisamos a forma como se estabeleceu o relacionamento com o parceiro local no Brasil.

Coube considerar também que dentro do tempo de existência do programa, criado em 1996, houve algumas trocas de parcerias internacionais, já que o IMPM já esteve presente em países como Japão e França com os quais interrompeu seu funcionamento em detrimento de novas escolhas como, por exemplo, é o caso no caso do Brasil e da China.

Dessa forma quando perguntamos ao idealizador do programa, Henry Mintzberg, qual havia sido sua motivação para a criação e realização do IMPM como um projeto essencialmente internacional, sua resposta foi:

[...] Então, eu acho que um bom programa é aquele que reúne pessoas de diferentes países. A chave para ver as nossas melhores características não é ser global, mas ser "parte do mundo!"

[...] Nós não queremos que as pessoas tenham um molde global, todos iguais. Nós queremos que eles sejam individualmente do mundo. Queremos que eles entendam outros mundos e penetrem neles, profundamente. [...] Então, eu acho que este foi o grande incentivo para torná-lo internacional desde o início ".

Neste trecho, podemos perceber a disposição inicial de Mintzberg em promover um programa internacional, sem prejuízo das questões locais, que reforça toda a argumentação teórica deste mesmo professor que pode ser encontrada em fontes documentais, como livros, artigos, sites e documentos oficiais do programa desde meados dos anos noventa (MINTZBERG, 2004). Por outro lado, podemos argumentar até que ponto um programa oriundo de países dominantes pode deixar de atuar com sua pressão habitual sobre os países periféricos sem representar as ameaças expostas por Santos $(2003,2006)$ no bojo dos fenômenos de localismo globalizado e globalismo localizado. Ou seja, será que apenas a intenção de considerar um programa global no

RPGE - Revista on line de Política e Gestão Educacional, Araraquara, v. 22, n. esp.1, p. 244-264, mar., 2018. 
sentido de considerar com equidade todas as "partes do mundo" seria uma intenção possível de ser realizada?

Ainda corroborando esta visão segue o depoimento de outro membro do corpo docente que esteve presente na administração do IMPM desde sua criação.

\begin{abstract}
"Para o termo "gestores globais" anexamos a definição de gestores que eram os Deuses que impulsionaram a globalização, e acho que havia a sensação, dentro do programa, de que este era um processo que fazia o mundo inteiro se encaixar em um modelo americano ou anglo saxão. E ao conceito de "gestores do mundo", por contraste, anexamos a definição de que gerentes deveriam entender que existiam muitas maneiras diferentes de fazer as coisas no mundo.” (E. 02)
\end{abstract}

Neste depoimento fica mais evidente que o IMPM nasce e é conduzido, pelo menos em teoria, como um programa que tenta desenvolver uma relação simétrica, ou menos assimétrica, entre os países 'anglo-saxões' e os países ou os países emergentes, onde o "local" pode ser tão relevante quanto o global. Por outro lado, cabe considerar que na visão de poder que contempla a definição de dominação, nunca é fácil ou mesmo possível para os atores envolvidos na teia de relações internacionais deterem a consciência e o controle que garantam interações menos assimétricas (FLEMING. SPICER, 2014; MIGNOLO, 2000).

Outro aspecto analisado nesta categoria diz respeito à escolha não só de países, mas de cidades específicas para o estabelecimento das parcerias locais. De acordo com Held (1999) o fato de nos atermos a fenômenos ocorridos em grandes cidades, seja em países periféricos ou centrais, pode por si mesmo reduzir o nível de características locais, uma vez que atualmente as grandes cidades experimentam uma aproximação e pasteurização já sofrida pela influência dos hábitos globais, melhor dizendo, padrões de comportamento importados ou impostos pelos países desenvolvidos.

Desta maneira, a intencionalidade e a preocupação com a escolha de locais dentro de locais, ou cidades e instituições parceiras dentro do estabelecimento do projeto de internacionalização do programa podem ser compreendidos neste trecho da entrevista de Henry Mintzberg:

Fui eu que fiz lobby para o Brasil e para o Rio. Eu disse: São Paulo, não. Eu não quero ir para São Paulo. Eu disse claramente, nós temos que ir para o Rio. [...] Se estivéssemos em SP, teríamos muito mais do pensamento empresarial convencional que se tem em todo lugar. [...] Estamos em Montreal, e não em Toronto. Toronto é o centro de negócios. Estamos em Bangalore, não em Nova Delhi. Isso,

RPGE - Revista on line de Política e Gestão Educacional, Araraquara, v. 22, n. esp.1, p. 244-264, mar., 2018. 
provavelmente, reflete, em parte, o meu ponto de vista antiestablishment (contra o pré-estabelecido) do mundo, também.

Percebemos assim que o local pode ir além do contexto de um país, ou de seu estereótipo cultural e que o IMPM considera esta questão em suas escolhas. Mintzberg deixa claro em seu depoimento que os locais onde se estabelecem as parcerias são escolhido de forma consoante com os princípios norteadores do programa, ou seja, com intencionalidade e de forma a privilegiar sua visão heterodoxa da gestão. Isso fica evidente quando ele expressa que espera encontrar no Rio de Janeiro mais diferença ou particularidades que se destaquem do contexto global ou pasteurizado do mainstream da gestão. Este ponto reforça que, a princípio, e em tese, o programa pretende considerar com maior ênfase as questões locais (SANTOS, 2006; HELD, 1999).

Quanto à possibilidade de realmente estabelecer relações menos assimétricas de poder em seu processo de internacionalização desde sua criação em 1996, pode-se ouvir outros depoimentos como:

[...] Então, se você voltar ao início, o programa foi concebido por pessoas da McGill, Insead e Lancaster. Ou seja, dentro dele não havia, absolutamente, nenhum país emergente... (...). Se era a Índia, o Brasil ou a China, a ideia era que as diferenças culturais eram uma parte importante da apreciação da gestão e da educação em gestão. Mas as ideias centrais, de como o programa se originou, realmente não tinha uma visão muito sistemática sobre essas economias emergentes "(F. 3). (Grifo da autora)

Neste trecho, podemos considerar os traços de que o programa foi desenvolvido por acadêmicos de países centrais ou dominantes, que mesmo com a intenção explícita de propiciar uma experiência equilibrada entre vários locais, lidaram desde o início com esta questão no sentindo de experimentar as dificuldades de ser capaz de permitir ou não a manutenção de relações desiguais no campo da educação em gestão.

\section{Inserção dos Países Emergentes}

Quando analisamos a segunda categoria, que trata especificamente da inserção dos países emergentes na agenda do IMPM procuramos compreender como as pessoas envolvidas na internacionalização do programa descrevem estas atividades de planejamento e seus processos de ação, principalmente os relacionados às mudanças mais recentes, que ocorreram nos últimos quatro anos, de parcerias com universidades, mais especificamente no caso do Brasil.

RPGE - Revista on line de Política e Gestão Educacional, Araraquara, v. 22, n. esp.1, p. 244-264, mar., 2018. 
Em primeiro lugar é preciso explicitar que a maior parte dos mestrados internacionais tem praticado o mesmo modelo em termos de processo de internacionalização e escolhas de países emergentes para o estabelecimento de parcerias. Dessa forma, não podemos dizer que o IMPM seja totalmente pioneiro nesta proposta, pelo menos em relação a sua posição atual uma vez dentro de seus cinco módulos três funcionam no Brasil, na China e na Índia.

No depoimento de um membro do corpo diretivo da instituição parceira no Brasil pode-se recuperar uma parte do histórico do processo de negociação e a percepção do entrevistado sobre sua condução.

Acredito que instituições de ensino e universidades são organizações que se organizam a partir do caos, em processos emergentes e pouco planejados [...] esse processo deriva de quatro fatores: oportunidade, atores, problemas e soluções. E acredito que nesse caso tenha ocorrido exatamente esse padrão. $(F .7)$

O mesmo respondente opina sobre a questão do interesse do programa pelo estabelecimento da parceria local, considerando o fato de o IMPM ser um programa reconhecido internacionalmente como vinculado a instituições de países centrais, porém com aparente discurso de interesse e respeito pelas características locais (MIGNOLO, 2011; FLEMING, SPICER, 2014, 2007).

Tenho dúvidas que eles estejam realmente tão interessados nas questões locais. Vamos fazer uma divisão. Acho que o IMPM é um caso a parte, existem outros programas, como o EMBA, o Gemba, e vários outros, mas na maioria deles, eu vejo isso como uma forma de criar um produto que seja interessante, funciona como uma característica de marketing, de venda do produto. Quer dizer, fazer os módulos internacionais em vários países e nesse caso os países emergentes tem funcionado como um atrativo $(F .7)$.

Este trecho pode ser contrastado com o depoimento de um dirigente do IMPM que resgata as raízes do estabelecimento de parcerias internacionais do programa ao longo do tempo e suas razões para a mudança progressiva rumo aos países emergentes.

Eu acho que, no início (do programa), o mundo era muito diferente. Há 17 anos, quando o IMPM foi criado, o Japão e a Coréia eram participantes muito importantes no mundo. E, por isso, a lógica dos cinco membros era parcialmente o resultado de contatos e de que quem era percebido como sendo os jogadores dominantes do mundo. Então, a oportunidade surgiu quando duas escolas desistiram [...] foi o caso do Insead na França e também os dos coreano e japonês. 
[...] Insead teve uma mudança de diretoria e uma estratégia diferente. Houve alguma mudança política na situação da Coréia e a escola não foi autorizada a fazer o IMPM novamente. Nós, definitivamente, precisávamos trazer novos países do mundo em rápido desenvolvimento. E, claro, China e Brasil seriam participantes evidentes. Eles foram os dois participantes mais óbvios, devido à importância de seu rápido crescimento no mundo. E isso foi uma grande oportunidade para que nós não estivéssemos mais apenas (atuantes) no Norte, não só entre antigos participantes dominantes, mas trazendo dois novos membros com mentalidades totalmente diferentes (F. 5). (grifo da Autora)

Neste depoimento nos chama a atenção, em primeiro lugar, que a saída de países como Japão e França aconteceu por que estes países quiseram, por diferentes motivos, se desligar espontaneamente do programa. A partir deste momento o IMPM teve que buscar novas parcerias e lhes pareceu natural que a escolha fosse feita na direção dos países emergentes/periféricos, especificamente China e Brasil. Ou seja, não houve a identificação de um momento específico em que a direção do IMPM parou e deliberadamente planejou a troca dos parceiros ou identificou a necessidade de realizar esta mudança com a intenção premeditada de escolha de novos e específicos parceiros (ZADJA, 2005; HELD, 1999).

Em segundo lugar chama a atenção o fato do depoente ter expressado de forma bastante explícita que trazer mais dois novos parceiros, que não seriam da parte dos 'jogadores dominantes do mundo', como Brasil e China estariam adequados aos conceitos e propósitos do programa em expandir mentes e trazer elementos locais de gestão que pudessem agregar conhecimentos locais ao tema de forma a enriquecer a experiência de todos os envolvidos, corpo docente, participantes e organizações (MIGNOLO, 2000; FARIA, 2013).

No entanto, devemos chamar a atenção para um fato relevante. Apesar de muito ter sido dito sobre a necessidade de manter e respeitar traços locais em uma relação menos assimétrica de poder, é surpreendente constatar que apesar da troca de parceiros internacionais ao longo de usa trajetória de quase vinte anos, o IMPM manter os 'mindsets' dos módulos inalterados. Por exemplo, quando houve a troca da França pelo Brasil não aconteceu uma troca do 'mindset' deste módulo. Logo, se o intuito do programa em seu processo de internacionalização é ressaltar as vivências locais, tanto em termos culturais quanto em termos de conhecimento em gestão parece improvável que países tão distintos quanto França e Brasil possam se acomodar de maneira natural dentro de uma mesma perspectiva, no caso o mindset relacionado à 'ação'. Da mesma

RPGE - Revista on line de Política e Gestão Educacional, Araraquara, v. 22, n. esp.1, p. 244-264, mar., 2018. 
forma como na mudança do Japão para a China, poderia ter sido questionada a continuidade do mindset colaboração.

$\mathrm{Na}$ verdade, poderíamos questionar o porquê da manutenção, ao longo dos mais de vinte anos do programa, do eixo central de mindsets Inglaterra/reflexão e Canadá/análise de um lado, e de outro Índia/visão de mundo. Devemos nos perguntar se nesta continuidade não estaria implícita uma divisão internacional na produção de conhecimento em que o centro produz ciência e a periferia produz cultura (Mignolo, 2011). Ora, reflexão e análise estão centralmente ligados ä produção de conhecimento e, dentro dessa lógica, ao manter a produção da ciência no mundo anglo-saxão, não faria diferença em que outra parte do globo se aprenderia um pouco de cultura local a partir dos mindsets visão de mundo, colaboração e ação. Em outras palavras, a própria alocação dos mindsets seria contrária à lógica de construção do IMPM como um mestrado diferenciado do mainstream anglo-saxão.

\section{Conclusões}

O objetivo deste estudo foi verificar como ocorreu a estratégia de internacionalização do IMPM, mestrado internacional de Henry Mintzberg, e, dentro desse processo, analisar como se deu o estabelecimento da parceria entre o IMPM, com uma instituição brasileira no ano de 2012.

Dentro deste escopo coube procurar entender que a educação deve ser considerada como um ato geopolítico, mas que, ao tecer esta consideração é preciso também refletir que a educação, da maneira como tem sido praticada nas últimas décadas, requer que nos situemos de alguma maneira, dentro de um sistema que opera uma relação desigual de poder dentro da sociedade.

Assim, neste cenário consideramos como se problematizam os impactos da globalização na educação em gestão, com foco nas alterações ocorridas no contexto internacional contemporâneo, principalmente em termos da inserção de países periféricos/emergentes como Índia, China e Brasil, na pauta dos programas internacionais de educação em gestão. Para tanto, devemos verificar se as mudanças ocorridas neste cenário vêm acompanhadas de transformações sociais substanciais, e se estas serão suportadas por um sistema de educação próprio, capaz de criar e respeitar padrões locais dos países periféricos, ao invés de apenas importar aqueles já estabelecidos e impostos pelos países centrais, também denominados desenvolvidos. 
Desta forma, a partir dos resultados obtidos podemos concluir que os países periféricos que hoje integram o IMPM, e especialmente o Brasil, não escolheram participar do programa, na verdade eles foram "escolhidos" pela direção do programa, ou seja, a partir de países centrais que compõem sua administração. Assim, ao serem mais uma vez selecionados ou convidados, notamos que ocorre um padrão de repetição seguido pelo mercado de educação internacional que domina o setor e que de certa maneira impões o mesmo modelo de dominação e assimetria presente nas relações entre países periféricos e centrais.

Também discutimos que o fato do programa ter trocado parceiros como França por Brasil e Japão por China, mas não ter efetuado mudança em seus 'mindsets', pode ser considerado como um sinalizador de que realmente pode não ser tão simples praticar seu próprio discurso heterodoxo. Ou seja, o IMPM pode de fato não estar tão preocupado como afirma estar com as questões locais dos países com os quais desenvolve suas relações institucionais.

Assim, os resultados apresentados refletem que, mesmo ao se problematizar um programa internacional de mestrado de discurso diferenciado em termos de posicionamento ideológico, a educação em gestão atende a uma agenda imposta pela hegemonia acadêmica americana e eurocêntrica, no sentido de favorecer os interesses de países "centrais" em detrimento dos países menos desenvolvidos ou "periféricos". Afinal, segundo a lógica imposta pelos próprios países centrais cabe a eles produzir conhecimento, e a nós periféricos nos resta produzir cultura, folclore.

Esperamos que a consideração do fenômeno de internacionalização dos programas de educação em gestão, a partir de uma perspectiva crítica, possa amplificar as vozes dos países periféricos e proporcionar um maior equilíbrio entre a produção e consumo de conhecimento em gestão no cenário mundial contemporâneo. É necessário trabalhar sobre a perspectiva de que haja um movimento mais dialógico entre centro e periferia, onde não só os aspectos culturais destes países sejam considerados, mas também sua produção de conhecimento possa ser reconhecida.

Acreditamos assim, que nossa contribuição seja fornecer uma visão crítica e reflexiva do fenômeno e os correspondentes questionamentos para futuras pesquisas sobre a educação em gestão em um cenário que possa ir além do global, sendo na verdade um cenário de múltiplos locais do conhecimento.

Ainda nestes termos, reforçamos que é necessário refletir sobre a expansão e internacionalização de instituições e organizações que compõem e disseminam o 
sistema de conhecimento pelo mundo. Todo esse corpo de agentes, como universidades, think tanks e institutos de pesquisa entre outros são responsáveis não apenas pela produção do conhecimento dominante, mas por sua legitimação e divulgação. Em outras palavras, é através do processo de globalização e das relações assimétricas que se desenvolvem entre estes países centrais e os demais países periféricos que se modela o padrão de consumo do conhecimento dominante, criando-se praticamente um novo modelo de colonização epistêmica.

\section{REFERÊNCIAS}

ALCADIPANI, R.; ROSA, A. From global Management to glocal Management: Latin America Perspectives as a counter-dominant management epistemology. Canadian Journal of Administrative Sciences, v.28, n.4, p. 453-466, 2011.

ALVESSON, M.; SKOLDBERG, K. Reflexive Methodology: New Vistas for Qualitative Research. London: Sage Publications, 2000.

BANERJEE, S.; LINSTEAD, S. Masking subversion: neocolonial embeddedness in anthropological accounts of indigenous management. Human Relations, v.57, n.2, p. 221-247, 2004.

BERTERO, C. Os Desafios da produção de conhecimento em administração no Brasil. Cadernos EBAPE.BR, v. 1, n. 1, p. 181-196, 2013.

CLEGG, S.; BARRETT, M.; CLARKE, T.; DWYER, L.; GRAY, J.; KEMP, S. E.; MARCEAU, J. Management Knowledge for the Future: Innovation, Embryos and new Pardigms. In: CLEGG, S.; PALMER, G. (Eds.). The Politics of Management Knowledge. London: Sage, p. 190-236, 2006.

CLEGG, S.; PALMER, G. Introduction: Producing Management Knowledge. In: CLEGG, S.; PALMER, G. (Eds.). The Politics of Management Knowledge. London: Sage, p. 1-18, 1989.

CUNLIFFE, A.; LINSTEAD S. Introduction: teaching from critical perspectives.Management Learning, v. 40, n.1, p.5-9, Feb., 2009.

CZARNIAWSKA, B. A Theory of Organizing.Cheltenham, UK; Northampton, MA: Edward Elgar, 2008.

DAS, V. Subaltern Perspectives. Subaltern Studies, v. 6, p. 310-324, 1989.

DOZ, Y. Qualitative Research for International Business. Journal of International Business, v.42, p. 582-590, 2011.

DOS SANTOS, T. Globalization, Emerging Powers, and the Future of Capitalism. Latin American Perspectives, v.38, n.2, p. 45-57, 2011. 
FARIA, A.; IBARRA- COLADO, E.; GUEDES, A. Internationalization of management, neoliberalism and the Latin America challenge. Critical perspectives on international business, Vol. 6 Iss: 2/3, pp.97 - 115, 2010.

FARIA, A. Repensando redes estratégicas. RAC, Curitiba, v.15, n.1, p. 84-102, jan./fev., 2011.

FARIA, A. Sobre Desafios Geopolíticos para a Pesquisa em Administração. Cadernos EBAPE.BR., v.11, n. 1, p. 181-196, 2013.

FLICK, U. An introduction to qualitative research: Theory, method and application. London: Sage, 1998.

FLEMING, Peter.; SPICER, André. Contesting the corporation: Struggle, power and resistance in organizations. Cambridge University Press, 2007.

FLEMING, Peter.; SPICER, André. Power in management and organization science. Academy of Management Annals, v. 8, n. 1, p. 237-298, 2014.

GUEDES, A. Pesquisa internacional em gestão: abordagem interdisciplinar com múltiplos níveis de análise. In: VIEIRA, M. M. F. V.; ZOUAIN, D. M. (Orgs.). Pesquisa Qualitativa em Administração. Rio de Janeiro: Editora FGV, 2005.

HARDY, Cynthia. Understanding power: bringing about strategic change. British Journal of Management, v. 7, n. s1, 1996.

HELD, D.; MCGREW, H.; GOLDBLATT, D.; PERRATON, J. Global transformations: politics, economics and culture. Cambridge: Polity Press, 1999.

HURRELL, A. Brazil and the Global Order. Current History, January, 2010.

JICK, T. D. Mixing qualitative and quantitative methods: triangulation in action. Administrative Science Quarterly, v.24, n.4, Qualitative Methodology, Dec., p. 602$611,1979$.

LOFLAND, J.; LOFLAND, L. Analyzing Social Setting: A guide for qualitative observation and analysis. London: Thomson, 1995.

MIGNOLO, W. Local Histories/Global Designs: Coloniality, Subaltern knowledge, and Border Thinking. Princeton, NJ: Princeton University Press, 2000.

MIGNOLO, W. The Global South and World Dis/Order. Journal of Anthropological Research, v.67, n.2, p. 165-88, 2011.

MILES, M. B.; HUBERMAN A. M. Qualitative Data Analysis. London: Sage Publications, 1994.

MINTZBERG, H. Managers not MBAs: A hard look at the soft practice of managing and management development. San Francisco: Barrett-Koehler, 2004.

RPGE - Revista on line de Política e Gestão Educacional, Araraquara, v. 22, n. esp.1, p. 244-264, mar., 2018. 
MINTZBERG H.; GOSLING J. Educating Managers beyond borders, Academy of Management Learning and Education, v.1, n.1, p. 64-76, 2002.

PFEFFER, J. Managers not MBAs: A hard look at the soft practice of managing and management development.Administrative Science Quarterly, v.49, n.3, p. 476-479, 2004.

PIEKKARI, R.; WELCH, C.; PAAVILAINE, E. The case studies as disciplinary convention: Evidence from international business journals. Organizational Research Methods, v.12, n.3, p. 567-589, 2009.

SANTOS, B. S. Reconhecer para Libertar. Rio de Janeiro: Civilização Brasileira, 2003.

SANTOS, B. S. Globalizations. Theory Culture Society, v.23, nos. 2-3, p. 393-399, 2006.

SANTOS, B. S. The University at the Crossroad. Human Architecture: Journal of the sociology of self-knowledge, v. X, n. 1, p. 7-16, 2012.

SCHNEIDER, S. C. National vs. corporate culture: Implications for human resource management. Human Resource Management, v.27, n.2, p. 231-246, Summer, 1988.

SILVERMAN, D. Interpreting qualitative data. London: Sage, 1993.

SOUDIEN, C. Inside but below: The puzzle of education in the global order. In: International Handbook on Globalization, Education and Policy Research. Global Pedagogies. Springer. Netherlands, 2005.

SPINK, P. Reforming the State: Managerial Public Administration in Latin America. London: Lynne Rienner Publishers, 1999.

TIKLY, L. Post-colonialism and comparative education. In: SOUDIEN, C.; KALLAWAY, P.; BREIER, M. (Eds.). Education, Equity and Transformation, Dordrecht Kluwer Academic Publishers, p. 603-621, 1999.

TOYOSHIMA, M. International Strategies of universities in England. London Review of Education, v.5, n.3, p. 265-280, 2007.

USUNIER, J. C. International \& Cross-Cultural Management Research. Sage: Publications, 1998.

WELCH, C.; PIEKKARI, R.; PLAKOYIANNAKI, E.; PAAVILAINEN, E. Theorising from case studies: Towards a pluralist future for international business research.

Journal of International Business Studies, v.42, p. 740-762, 2011.

ZAJDA, J. Globalization, education and policy: changing paradigms. In: ZAJDA, J. International Handbook on Globalization, Education and Policy Research: Global Pedagogies. Springer: Netherlands, 2005a. 
ZAJDA, J. International Handbook on Globalisation, Education and Policy

Research. Global Pedagogies. Springer. Netherlands, 2005b.

\section{Como referenciar este artigo}

TEIXEIRA, Ana Christina Celano.; WANDERLEY, Sergio Eduardo de Pinho Velho; OLIVEIRA, Fátima Bayma de. A gestão centro-periferia na internacionalização de mestrados executivos. Revista on line de Política e Gestão Educacional, Araraquara, v. 22, n. esp.1, p. 244-264, mar., 2018. E-ISSN:1519-9029.

Submetido em: 04/10/2017

Aprovado em: 14/12/2017 